\title{
Aero Submarine: a Theoretical Design
}

\author{
Sepehr Akramipour
}

Author:

Email: sepehrakramipour58@gmail.com

Phone: +989912503064

Institute:

Allame helli 6 middle school, Tehran, Iran

school@helli6school.ir

\begin{abstract}
Aero submarines (aerosubs) are vehicles that can both fly both in air and travel under water. The concept of dual aerial and aquatic vehicles emerged in 1939 when Russian engineer Boris Ushakov proposed the "flying submarine"[1], and this was followed by further developments including RFS$1^{[2]}$, convair project in $1964^{[3]}$, etc. however, to date, limited attempt has been diverted towards the advanced development of such aircraft. This is heavily influenced by challenges associated with the design and operation of the same. Based on the review of literature the authors aim to introduce a theoretical design for an aerosub (QFS-20) with a view to address the design and operation issues including power, entry to and exit from water.
\end{abstract}

Key words: theoretical design, aero submarine, aerial submersible vehicle, direct dive, water-air transition, air-water transition.

\section{I-Introduction}

Aero submarine, aerosub or flying submarine is a vehicle that can both fly and travel under water and can have military or civil use. In $1939^{[1 f]}$ Boris Ushakov proposed the concept of flying submarine and this was the starting step in the development of such vehicle.

The main challenge associate with the progress in this area is the design of aerosub that is capable of executing the required maneuvers for commercial and military purposes both in air and water. 
This paper will introduce QFS-20, a theoretical aero submarine design that would attempt to overcome the challenges associated with previous aerosub.

II-History of the aero submarines

A-Ushakov's flying submarine

Between 1934 and 1938, in the early years of WWII, Ushakov Dzerzhinskiy, a cadet from the Russian Navy proposed a hybrid vehicle which had the capability of carrying up to three persons. With weight of approximately 15 tons, the vehicle could fly a distance of $800 \mathrm{Km}$ at the speed of $200 \mathrm{Km} / \mathrm{h}$, and could dive down to 50 meters depth underwater moving at speeds of 3 knots (figure 1). It was known as the LPL (Russian abbreviation of Flying Underwater Boat). However, a prototype of the LPL vehicle was never built ${ }^{[4][2]}$.
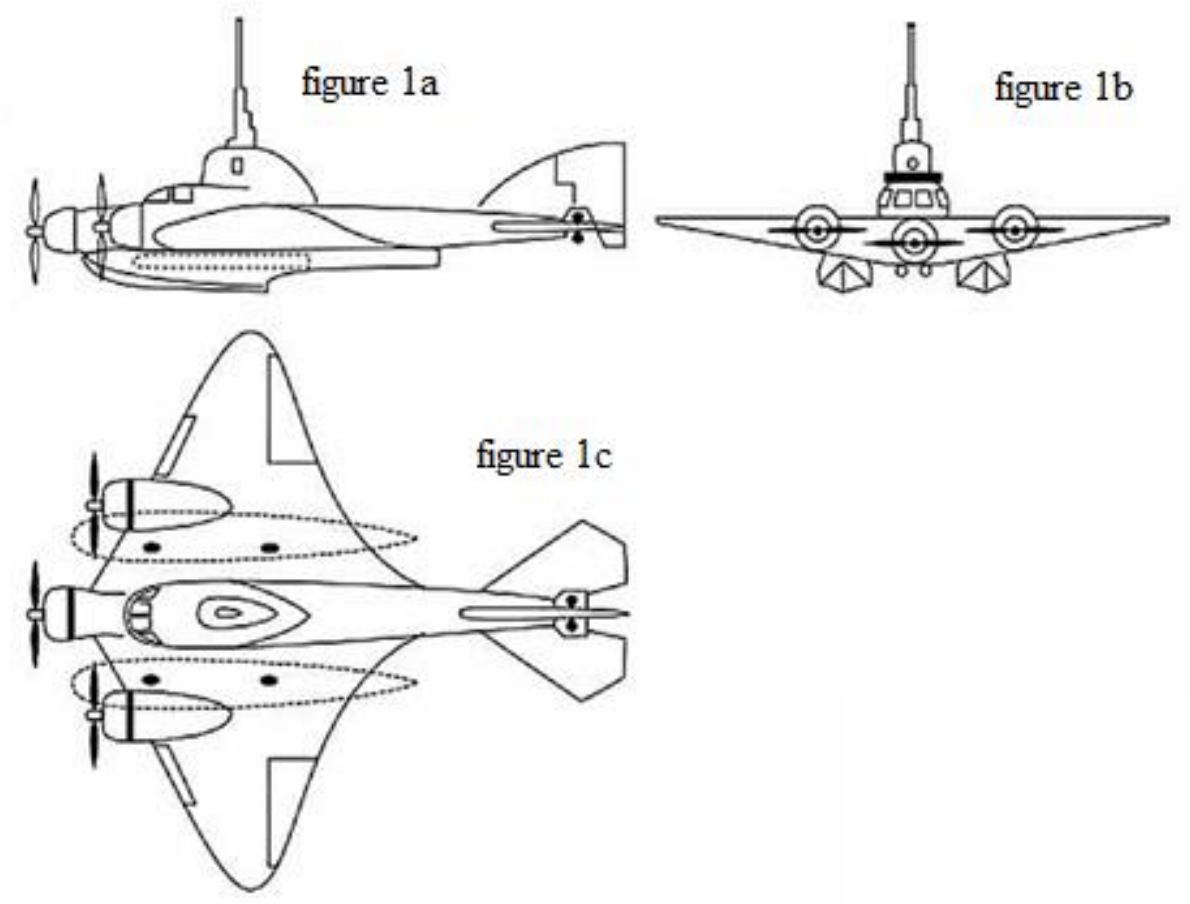

Figure 1: LPL [2]

Figure 1a: LPL Side view

Figure 1b: LPL front view

Figure 1c: LPL top view 


\section{B-Reid flying submarine}

In 1964, the world was presented with the first real hybrid vehicle with airplane and submarine capabilities. It was designed by a North American engineer Donald V. Reid, called the RFS-1 (Reid Flying Submarine 1) ${ }^{[2]}$.

An enthusiast of remote controlled submarines, Reid tested his ideas using modelsized submarines and built the first piloted prototype of his vehicle using parts of other aircrafts. Registered as N1740, the prototype could fly over 23 meters and move submersed for approximately 3.5 meters powered by an engine of about 65 hp. Figure 2 shows the Reid RFS-1 vehicle in one of its tests. To Reid and his son Don Reid (who continued to develop the project) disappointment, the military did not expressed any interest in financing the project, partly because the vehicle was unable to sustain its flight for long distances ${ }^{[2][5]}$.

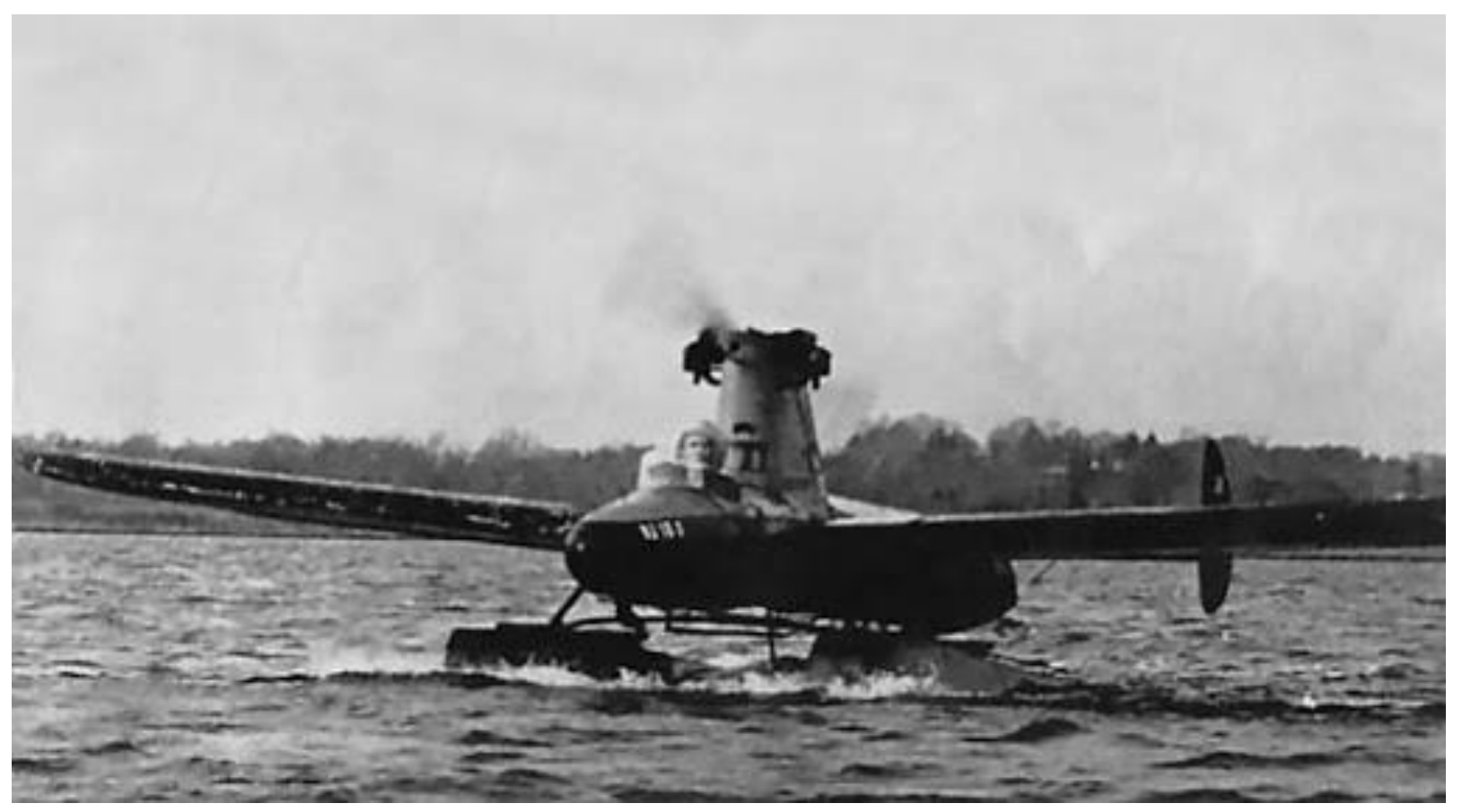

Figure 2:- RFS-1 [5] 


\section{C- Convair project in 1964}

In the early 1960s the Convair aircraft company proposed a small submarine that could travel at high speeds on the ocean surface using hydroskis or hydrofoils. The company had earlier developed the F2Y Sea Dart, a supersonic floatplane that employed water skis. This led to the Navy's Bureau of Naval Weapons - at the time responsible for aircraft development - awarding a contract to Convair in 1964 to examine the feasibility of a "submersible flying boat," which was called the "sub-plane". The Convair study determined that such a craft was "feasible, practical and well within the state of the art at the time".

The flying boat could alight and take off using retractable hydro-skis using three engines - two turbojets and one turbofan - the former was used for takeoff and the latter for long endurance cruise flight. Among the more difficult challenges of the design was the necessity of removing air from the engines and the partially full fuel tank to reduce buoyancy for submerging. Convair engineers proposed opening the bottom of the fuel tank to the sea, using a rubber diaphragm to separate the fluids and using the engines to hold the displaced fuel.

To submerge, the pilot would cut off fuel to the engines, spin them with their starter motors for a moment or two to cool the metal, close butterfly valves at each end of the nacelles, and open the sea valve at the bottom of the fuel tank. As the seaplane submerged, water would rise up into the fuel tank beneath the rubber membrane, pushing the fuel up into the engine nacelles. Upon surfacing, the fuel would flow back down into the tank. The only impact on the engines would be a cloud of soot when the engines were started. When the engines were started, their thrust would raise the plane up onto its skis, enabling the hull, wings, and tail surfaces to drain. The transition time from surfacing to takeoff was estimated to be two or three minutes, including extending the wings, which would fold or retract for submergence. Only the cockpit and avionics systems were to be enclosed in pressure-resistant structures. The rest of the aircraft was "free-flooding."

In an emergency the crew capsule would be ejected from the aircraft to descend by parachute when in flight, or released and float to the surface when underwater. In either situation the buoyant, enclosed capsule would serve as a life raft. The subplane was to be constructed using a high-density material, probably stainless steel, with titanium also being considered. Titanium or fiberglass was considered for the pressure capsule containing the two-man crew. Cargo could consist of mines; 
torpedoes; or, under certain conditions, agents to be landed on or taken off enemy territory. ${ }^{[3]}$

\begin{tabular}{|l|l|}
\hline air cruise speed & $280-420 \mathrm{~km} / \mathrm{h}$ \\
\hline air cruise altitude & $460-760 \mathrm{~m}$ \\
\hline air cruise radius & $555-925 \mathrm{~km}$ \\
\hline maximum gross takeoff & $<13,600 \mathrm{~kg}$ \\
\hline submerged speed & $5-10 \mathrm{knots}$ \\
\hline submerged depth & $7.6-23 \mathrm{~m}$ \\
\hline submerged range & $75-95 \mathrm{~km}$ \\
\hline submerged endurance & $4-10$ hours \\
\hline payload & $230-680 \mathrm{~kg}$ \\
\hline
\end{tabular}

table 1: Convair flying boat specification[3]

Figure 4:Convair flying boat

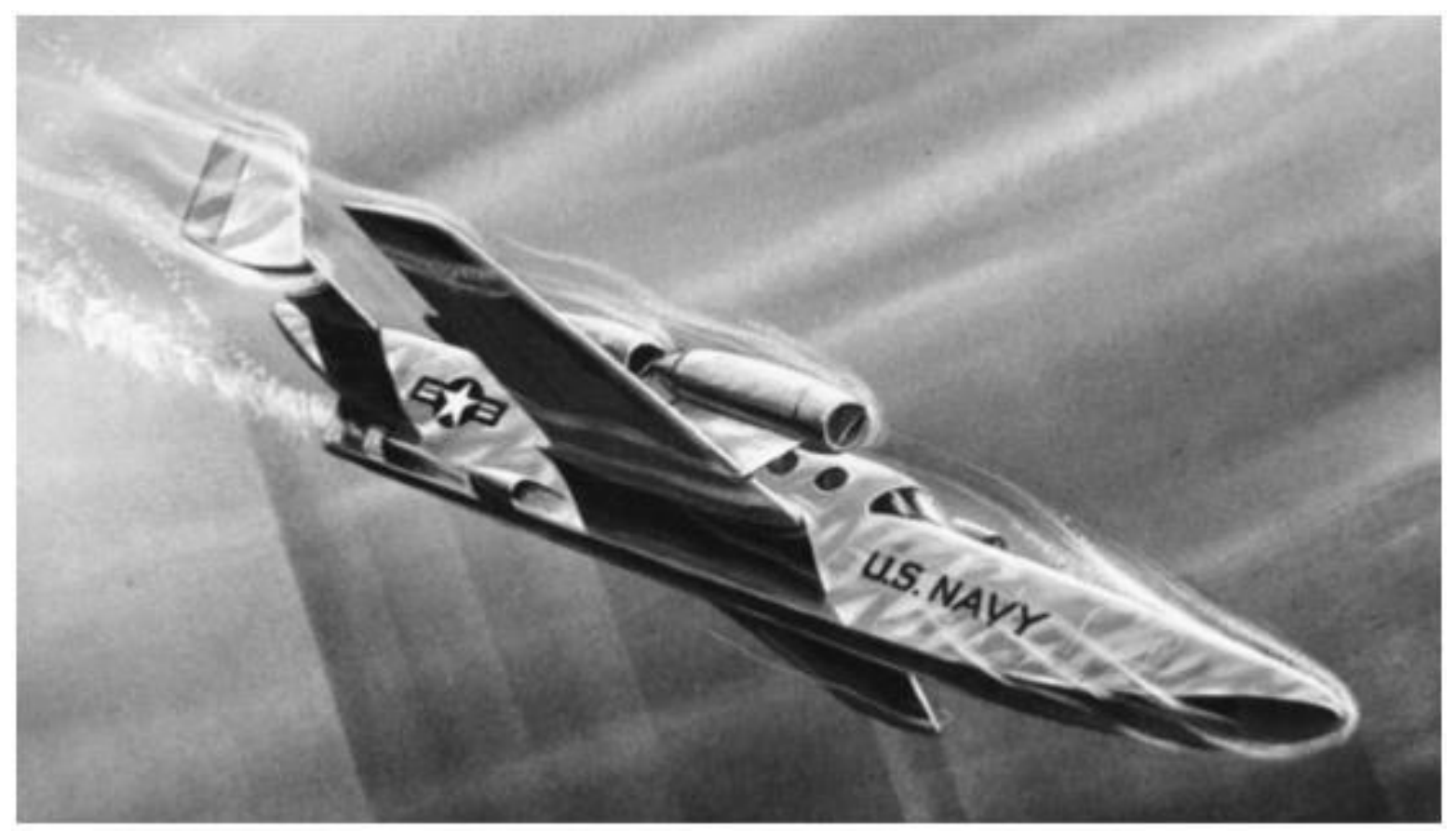




\section{D-Gannet}

The MIT Lincoln Laboratory 2011-2012 SCOPE team was tasked with identifying an opportunity in the field of robotics for a novel and unique system. MIT construct a proof-of-concept prototype for such system. The team was inspired by gannet birds (Morus bassanus) which are capable of a rapid, powerful, and streamlined transition from air to water and identified Project Gannet dedicated to building the robot. The proof-of-concept system offered insight into the challenges of designing such a unique system and paved the way for building more advanced and capable systems in the future ${ }^{[6]}$.

\begin{tabular}{|l|l|}
\hline country & USA \\
\hline Company/university & $\begin{array}{l}\text { MIT Lincoln } \\
\text { lab\& Franklin } \\
\text { Olin college }\end{array}$ \\
\hline year & 2012 \\
\hline engine & Hand lunched \\
\hline Underwater engine & Hand lunched \\
\hline Operation area & Underwater, air \\
\hline Entering the water & Direct dive \\
\hline Exiting the water & unavailable \\
\hline
\end{tabular}

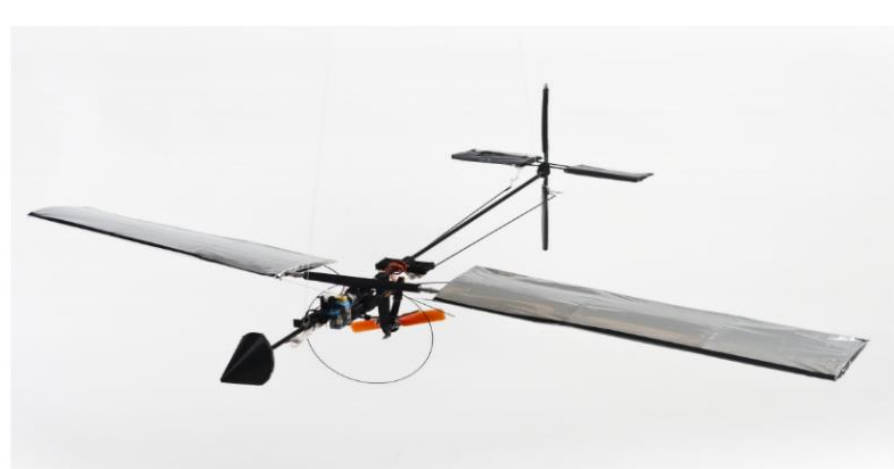

Figure 5: gannet picture

table 2: gannet specification[6]
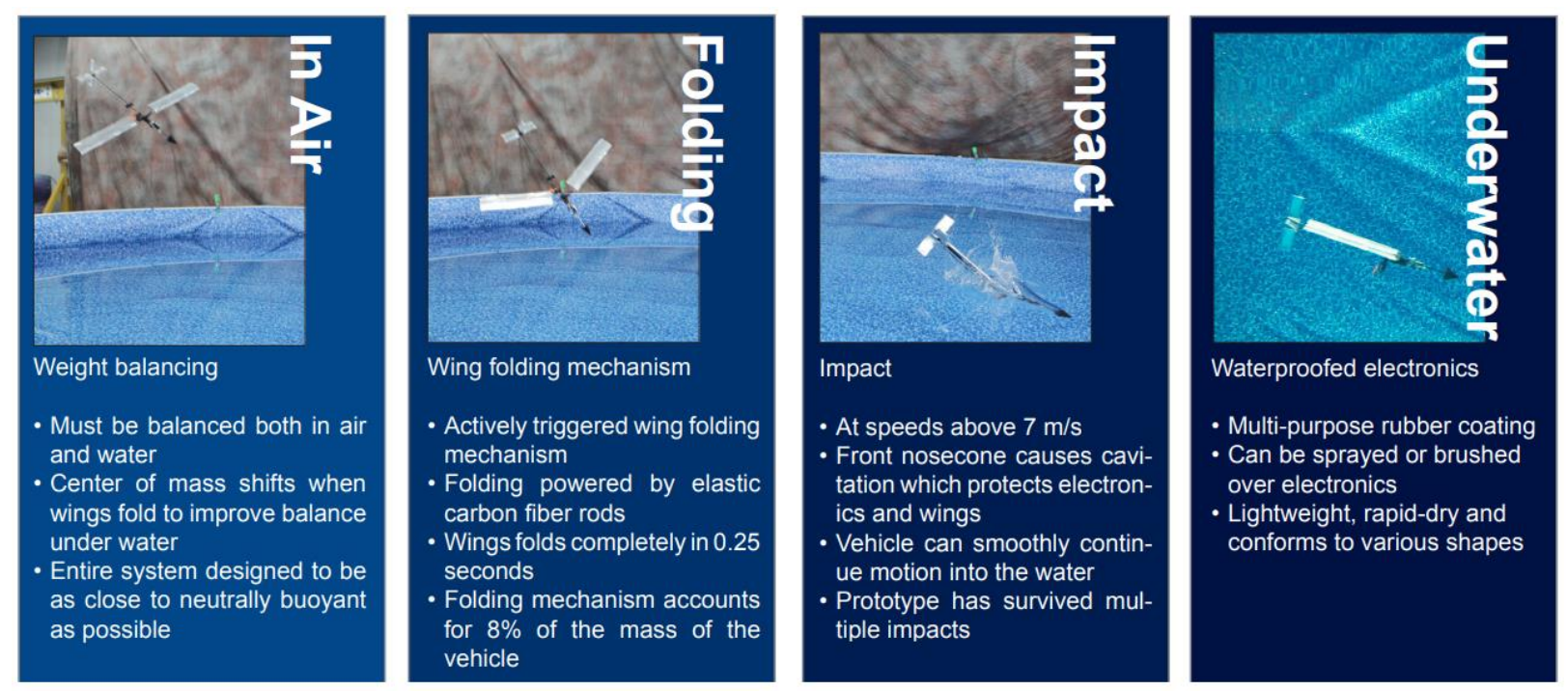
E-mimic gannet

\begin{tabular}{|l|l|}
\hline country & China \\
\hline Company/university & $\begin{array}{l}\text { beihang } \\
\text { university }\end{array}$ \\
\hline year & 2013 \\
\hline engine & Hand lunched \\
\hline Underwater engine & Hand lunched \\
\hline Operation area & Underwater, air \\
\hline Entering the water & Direct dive \\
\hline Exiting the water & unavailable \\
\hline
\end{tabular}

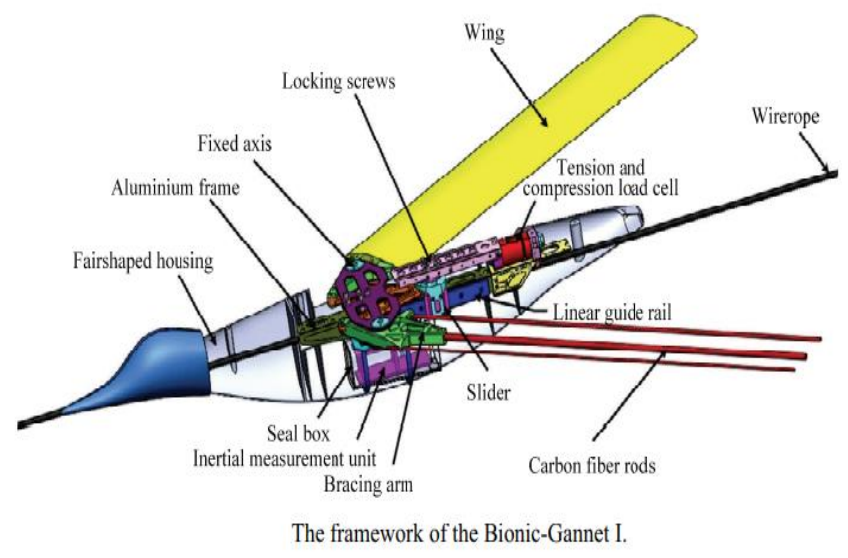

Figure 6: mimic gannet picture

table 3: mimic gannet specification[7]

The body configuration of the bionic gannet was designed referring to the data obtained from a living gannet and analysis of the results of the images and videos. The body was constructed of an aluminium frame which was used for mounting the measurement devices and supporting the streamlined housing. A tension and compression load cell and a seal box filled with an inertial measurement unit and all corresponding data acquisition circuits were fastened to the frame. The appearance of the housing was designed from biological data. The streamlined housing was made of carbon-fibre-reinforced plastic, and mounted on the frame to represent a gannet shape.

The wing and the bracing arm on each side were connected through three longitudinal carbon fiber rods. The bracing arm rotates around the fixed axis to drive the corresponding wing to fold back. The body length and the maximum wingspan (sweepback angle equals 0) were $900 \mathrm{~mm}$ and $1970 \mathrm{~mm}$, respectively. ${ }^{[7]}$

\begin{tabular}{llc}
\hline \multicolumn{1}{c}{ Parameter } & Living gannet & Mimic gannet \\
\hline Weight $(\mathrm{kg})$ & $3.286 \pm 0.226$ & 7.2 \\
Body length $(\mathrm{m})$ & 0.95 & 1.16 \\
Bill length (m) & 0.1 & 0.12 \\
Wing span (m) & $1.905 \pm 0.052$ & 2.10 \\
Mean wing chord (m) & $0.136 \pm 0.008$ & 0.15 \\
Aspect ratio & $14.07 \pm 0.096$ & 14 \\
Wing area $\left(\mathrm{m}^{2}\right)$ & $0.259 \pm 0.016$ & 0.276 \\
\hline
\end{tabular}

table 4 :mimic gannet information table ${ }^{[8]}$ 


\section{F-Flying squid Prototype}

In 2014, Siddall and Kovač from Imperial College published a review article on the study of the bionic design of aquatic-aerial amphibious unmanned platform in the journal of Bioinspiration \& Biomimetics ${ }^{[10]}$. Based on the bionic design method Inspire-Abstract-Implement raised previously ${ }^{[11]}$, they proposed the key design principles of aquatic-aerial amphibious vehicle: using a gannet-like plunge-diving strategy for water entry, folding wings for diving efficiency, flying-squid-like water jet propulsion for water takeoff and hydrophobic surfaces for water shedding and dry flight. Further, a proof-of-concept water jet propulsion mechanism was built to demonstrate the feasibility of the water jet propulsion. The mass of the mechanism was $2.6 \mathrm{~g}$. It could propel itself up to $4.8 \mathrm{~m}$ high, corresponding to 72 times its size. Therefore, this propulsion mechanism had high-power density, which had potential application prospects for AquaUAVs* and other bionic robots, such as jumping and swimming robots ${ }^{[9]}$.

AquaUAVs*: Aquatic unmanned aerial vehicles, UAVs that can operate in water and air. 


\section{III-Design}

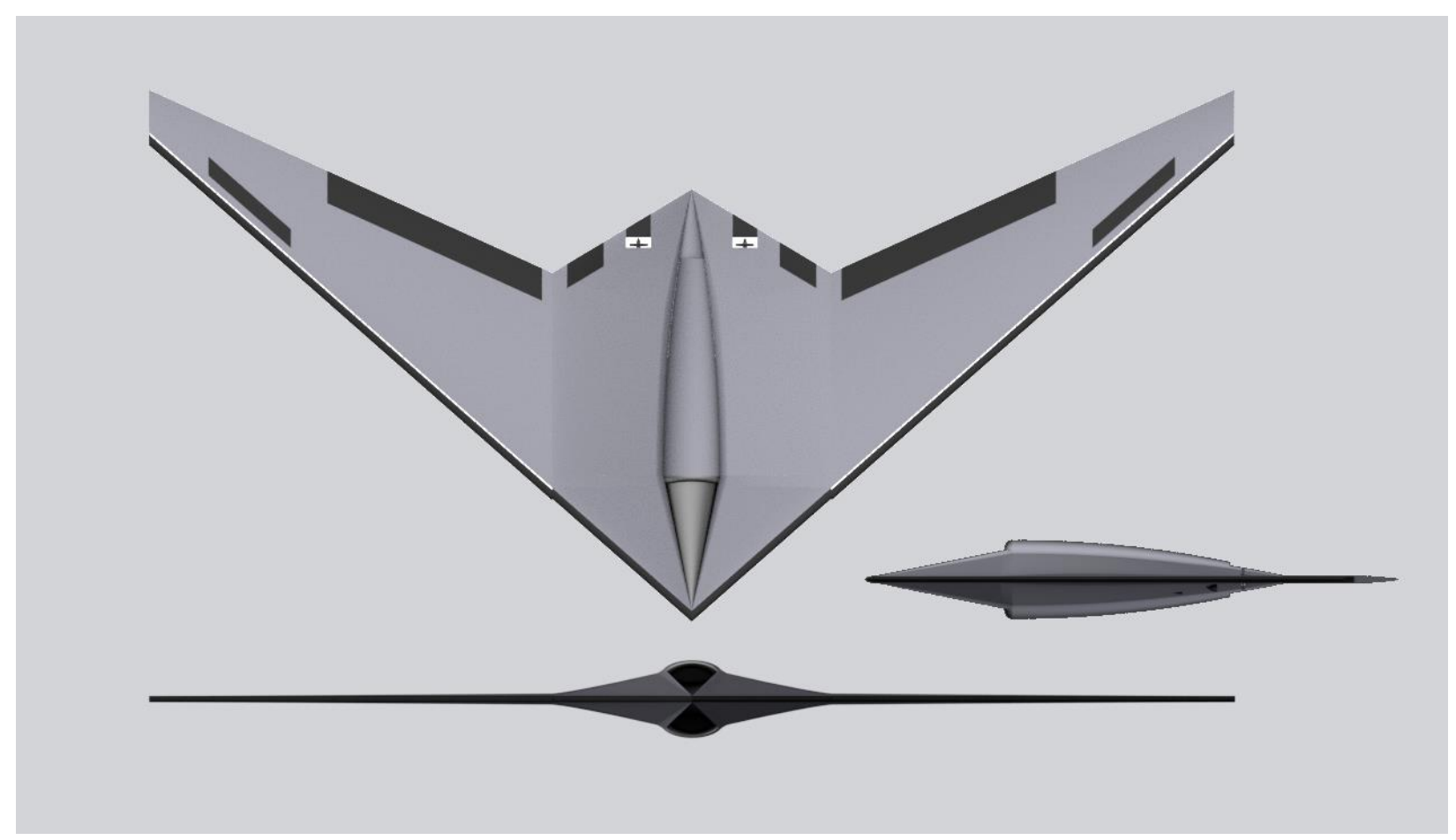

figure 7: QFS-20 top, front and side views

QFS-20 is a theoretical designed aero submarine, powered by jet engine during the flight and powered by 2 underwater propellers during the underwater travel.

Idea of designing QFS-20 came from the military reconnaissance operation. Recognizing process of a submarine or a ship by a small submarine might be so slowly. The solution is QFS-20, QFS-20 has designed to fly the distance from start point and the operation zone instead of underwater travel which decreases the during of the travel from start point to the operation zone. In the operation zone, QFS-20 will enter the water directly to keep itself stealth, when the operation of the QFS-20 in the operation zone is finished, it would fly to the lading point.

Being able to operate in 2 different environment is a big challenge in case of designing an aero submarine, the solution of this challenge for QFS-20 includes:

1. Hydrophobe surface which decreases the stickiness of water with surface

2. Rocket speed boosters which increases the speed underwater while exiting the water

3. Closable inlet and exhausts

4. Under water propellers 
One of the main points of QFS-20 is the direct entry and exit to and from water (fly-swim) rather than landing on water surface first and then travel underwater(fly-landing-swim). QFS-20 also exit water directly instead of previous design where the vehicle land on water surface and then takeoff (exiting the waterland-fly).

\section{Parts \& systems:}

\begin{tabular}{|c|c|}
\hline Jet engine system & Underwater engine system \\
\hline Jet engine & underwater engine fuel tanker \\
\hline Inlets & compressed air tanker \\
\hline Inlet doors & fuel transmission pipe \\
\hline Exhausts & air transmission pipe \\
\hline & underwater engine \\
\hline & propeller shaft \\
\hline & propeller \\
\hline & underwater elevator \\
\hline & underwater engine exhaust \\
\hline
\end{tabular}

Table 5: main systems parts table

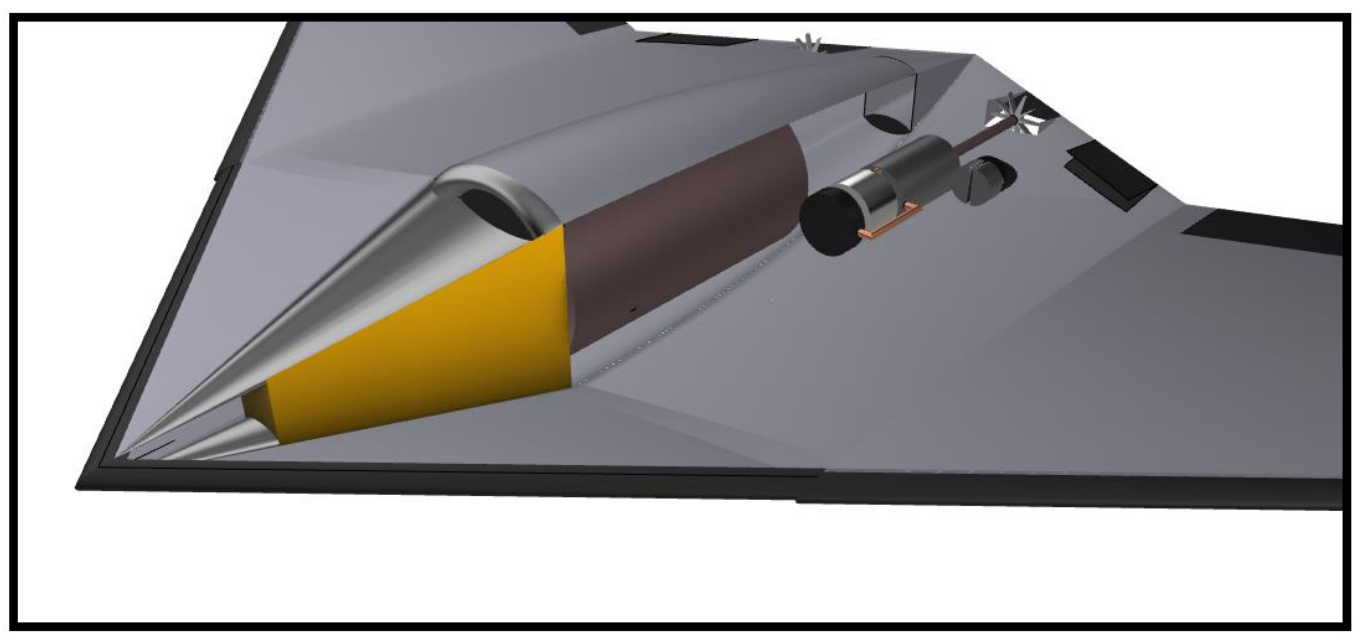

Figure 8: inner system parts of QFS-20

QFS-20 uses 2 main systems to work. each main system includes the main parts of an aero submarine.

These two systems are the most important parts (+ systems case) of QFS-20 and without them, QFS-20 is not able to fly or swim underwater 


\section{* jet engine system}

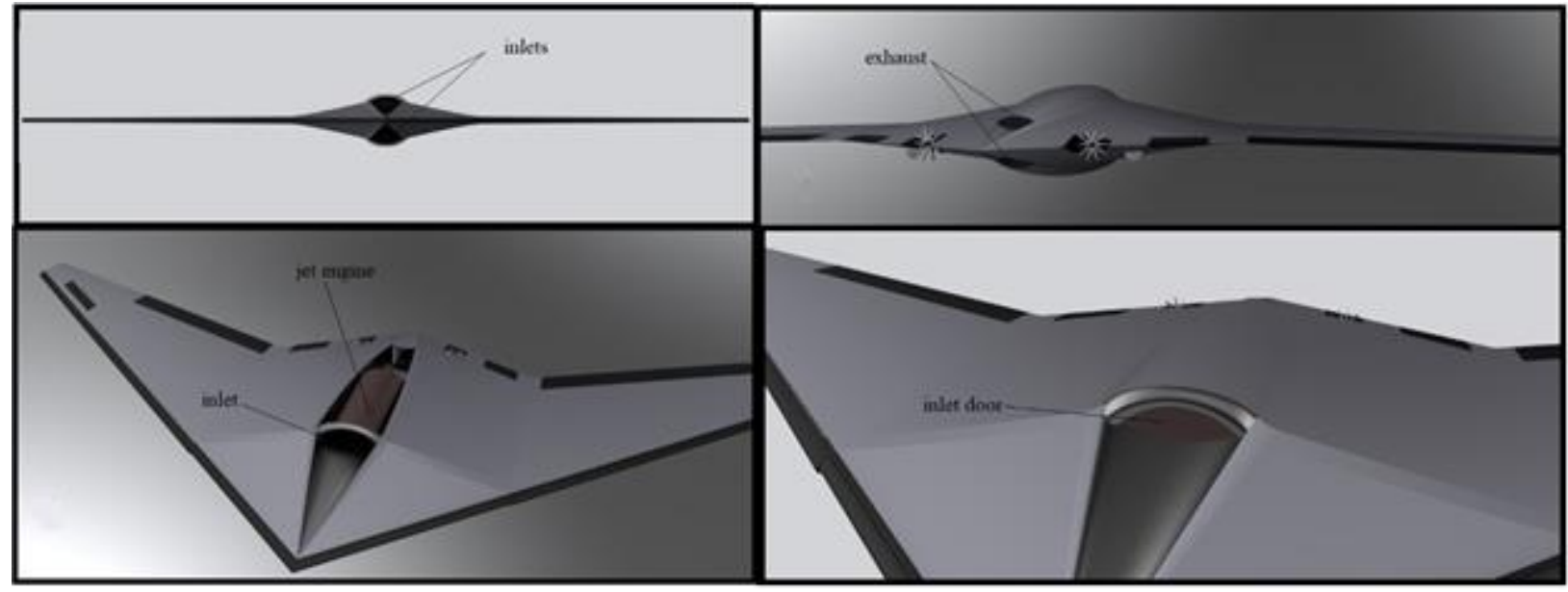

Figure 9: jet engine system parts

Jet engine system includes one jet engine, 2 inlets, 2 inlet doors and 2 way out exhaust, that can make enough thrust to make it fly and move on the ground.

To avoid entering water from inlets to the jet engine, two inlet doors have been designed that can cover and close the inlets while QFS-20 is under water.

When QFS-20 is in air and inlets doors aren't covering the inlets, the inlets doors will be under the inlets.

Due to the situation underwater, the jet engine system would be unusable and the underwater engine system will start working.

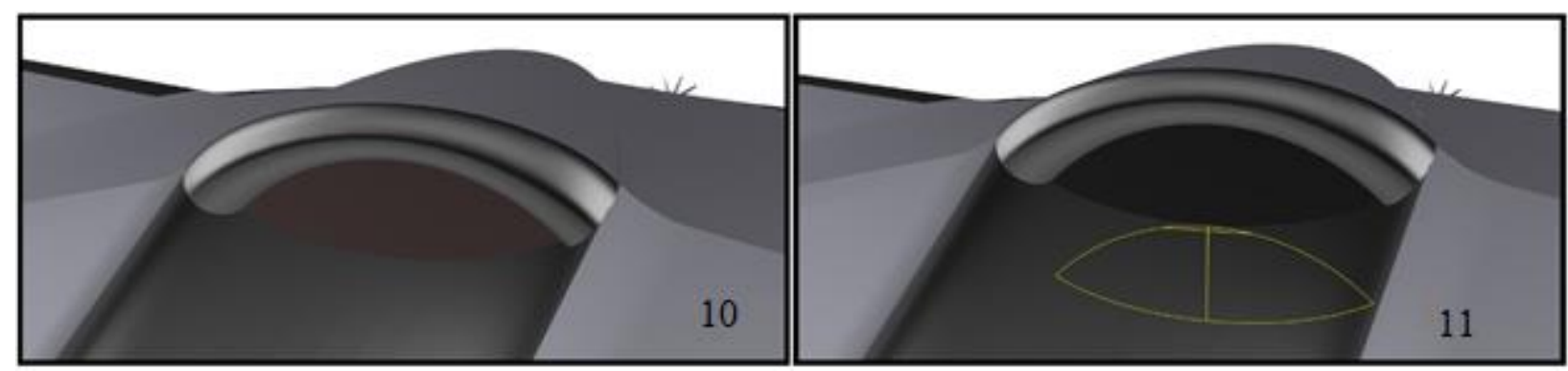

Figure 10: this picture shows the inlet when the door is covering the inlet (brown surface is the door) figure 11: this picture shows the inlet when the door isn't covering it, yellow curves shows the door position when it's not covering the inlet. 


\section{underwater engine system}

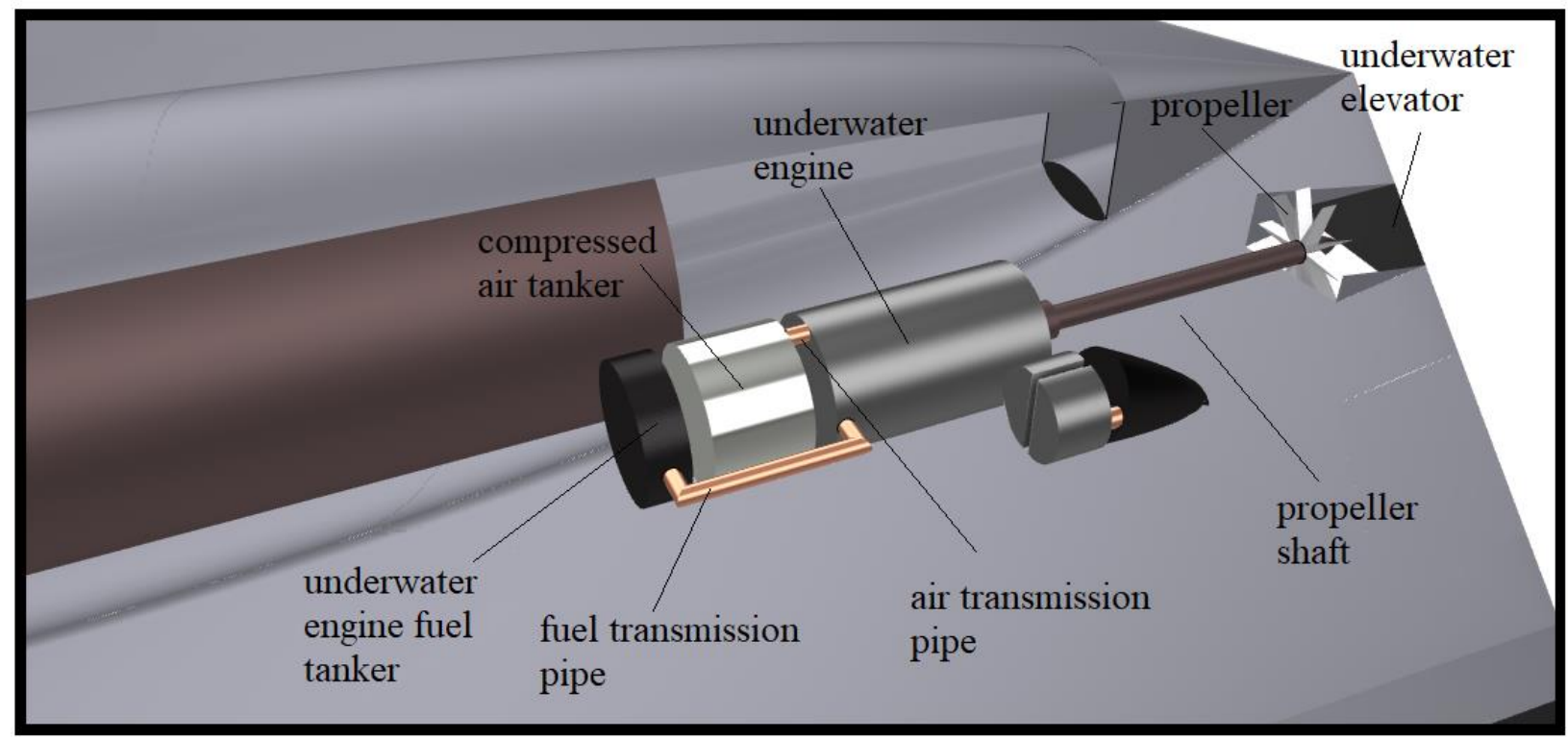

figure 12: underwater engine system parts.

The underwater system includes underwater engine fuel tanker, compressed air tanker, fuel transmission pipe, air transmission pipe, underwater engine, propeller shaft, propeller, underwater elevator and underwater engine exhaust. Underwater engine system will make QFS-20 travel underwater, an elevator behind each propeller (underwater elevators) enable QFS-20 to change the altitude faster than the elevators on the wing, the elevators will help QFS-20 change the altitude too.

This system starts working with the compressed air tanker. Air transports to the underwater engine via air transmission pipe and the fuel will transport to the underwater engine via the fuel transmission pipe. The underwater engine will start working following these two steps, the underwater engine will rotate the propeller shaft, and the shaft will rotate the propeller and make QFS-20 able to travel. while engine is burning the fuel, it will produce gas too, the gas will exit the engine from the exhaust under the underwater engine. 


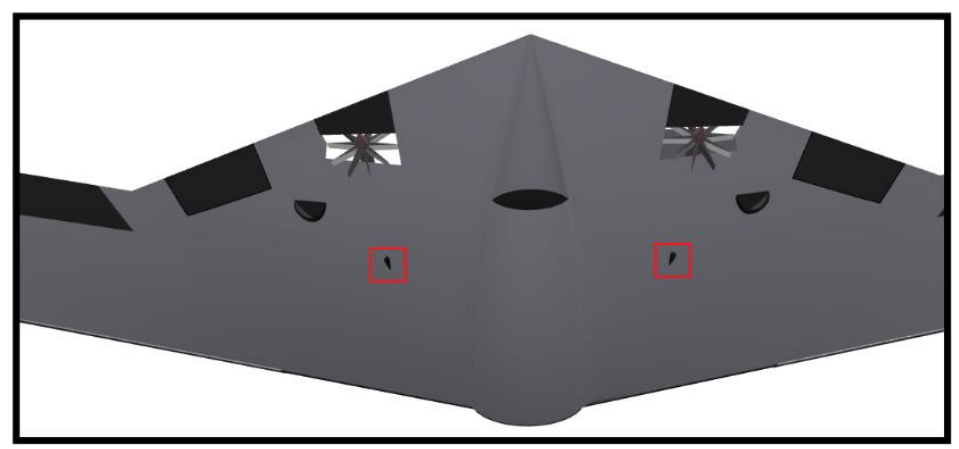

figure 13: underwater engine exhausts location (in the red squares)

\section{Dual role parts}

Double parts are the parts that operate in both flying and traveling under water. Any problem in one of these parts can make QFS-20 will have a direct impact on the operation and performance of the vehicle both in air and under water. These parts include; underwater speed boosters, systems case and control surfaces and leading edge slat.

\section{speed boosters}

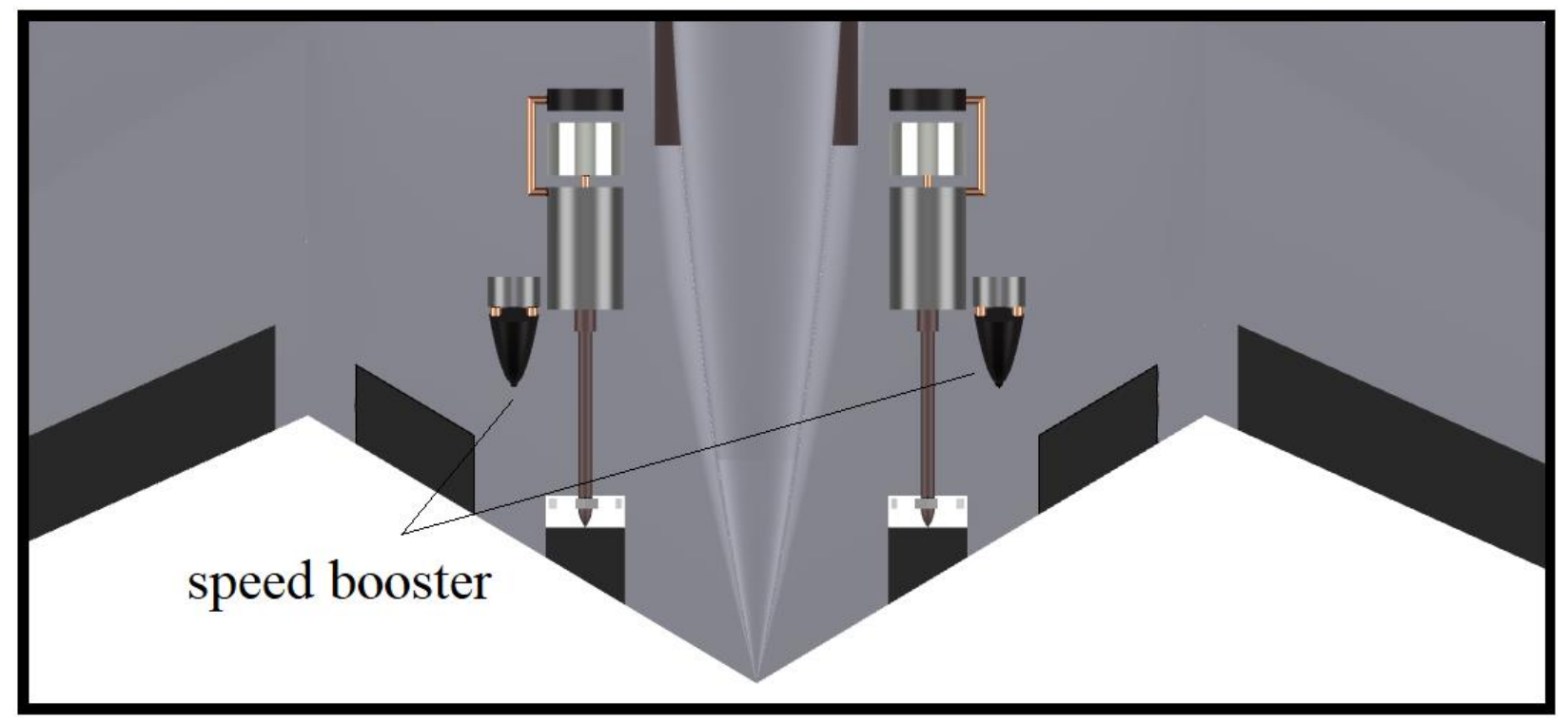

Figure 14: speed boosters location

Speed booster include a small rocket and fuel tankers. Because the aero submarine should reach a high speed underwater to be able to produce lift (while lift slat is helping to produce lift in low speeds) after exiting the water, the aero 
submarine can't reach the required speed with underwater engine, so these boosters will help the aero submarine to reach the required speed. When QFS-20 exit the water, the jet engine will start working, the speed booster will hold the speed in a specific speed to have lift without leading edge slats until the jet engine produce thrust.

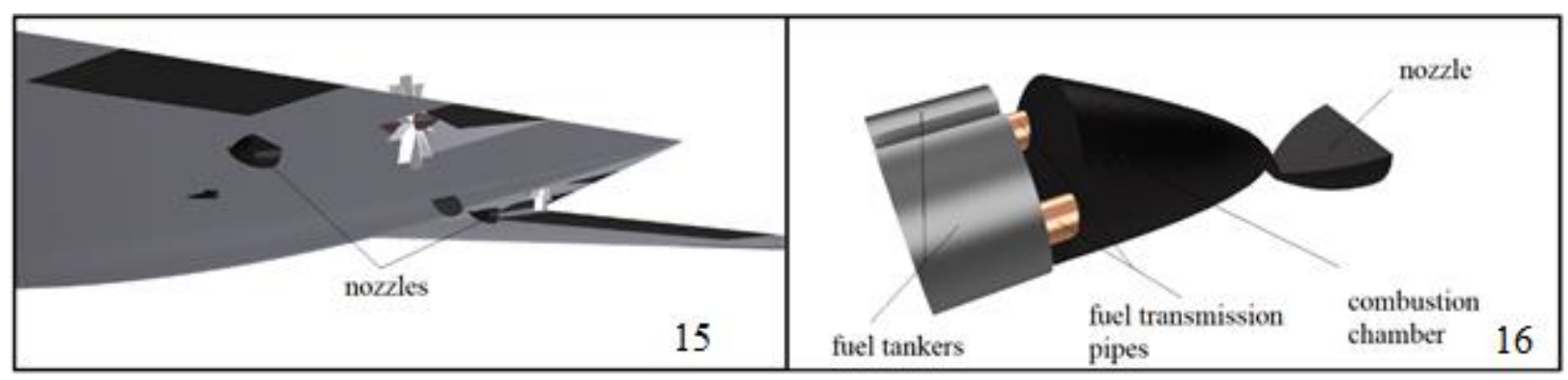

figure 15: location of speed boosters nozzle

figure 16: speed booster's parts name \& location

systems case

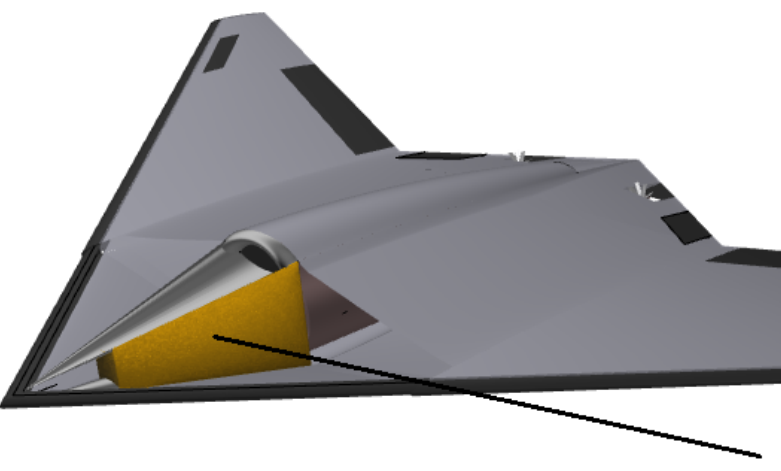

systems case

figure 17: systems case location

The system case is located in front of the jet engine. computers, controlling systems, antennas, sensors, etc are located in this case. One of the consideration for QFS-20 would be the incorporation of autopilot and artificial intelligence, 
because if disconnection happens, QFS-20 would analysis the disconnection duration, distance from the target and the airbase, and know if there is a problem in any part or not, and the decide what to do.

control surfaces and leading edge slat

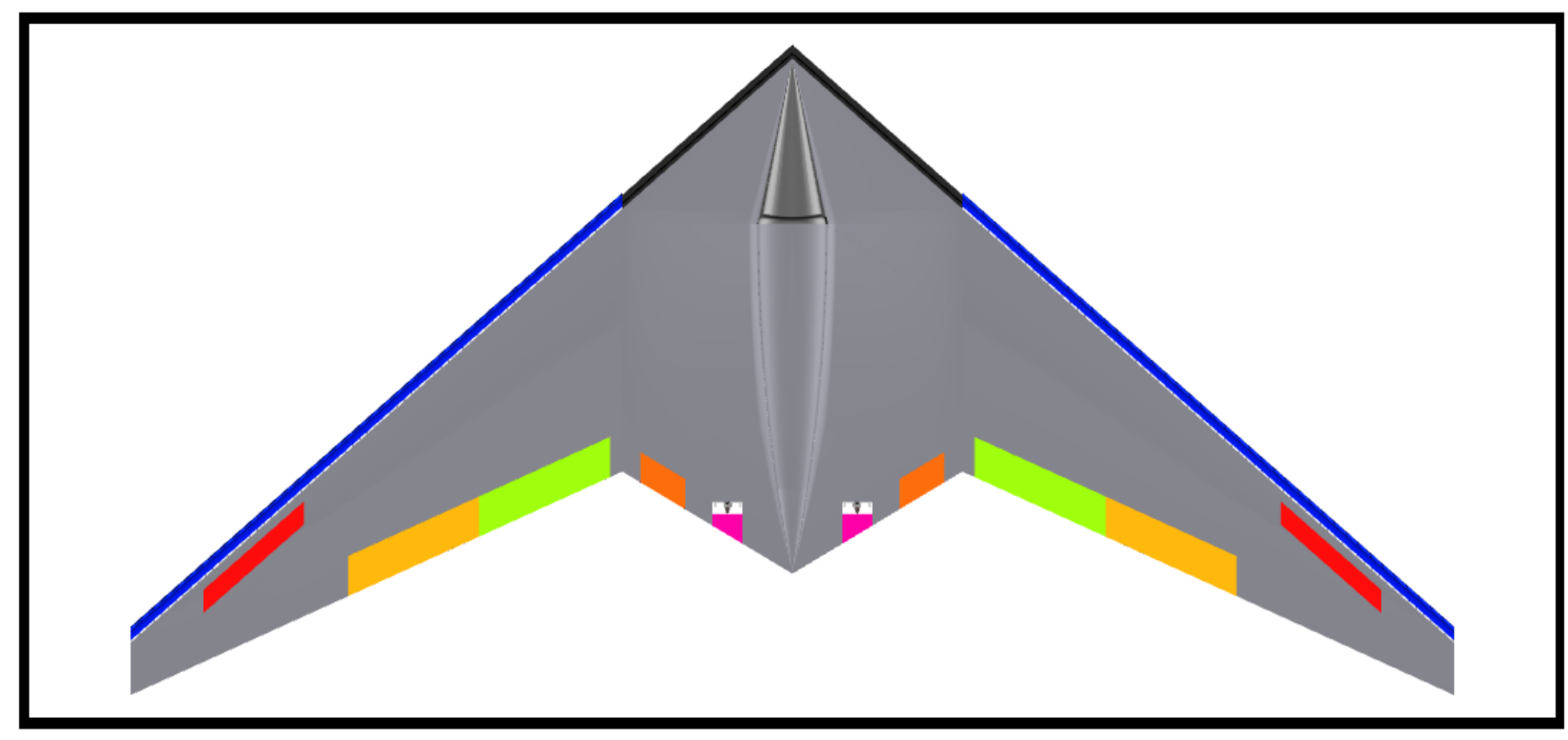

Figure 18: Blue parts are leading edge slats, spoilers are the red surfaces, ailerons are the yellow surfaces, green surfaces are elevators, orange parts are split drag rudders and pink surfaces behind the propellers are underwater elevators.

The leading edge slap main function is to provide the required performance following the exit from water. Because when QFS-20 has exited the water, the speed isn't enough to produce enough lift, so this situation can cause stall, the leading edge slat will go down to make QFS-20 able to produce enough lift and fly.

When QFS-20 is at water entry position, there is a short distance from the QFS20 and the water surface, control surfaces are in danger, the elevons positions limit are $-30^{\circ} 30^{\circ}$ and the split drag rudders positions limit are $0-60^{[12]}$, this suggest that the split drag rudders are in more danger so they should set to 0 (zero) degree to avoid losing it during air-water transmission.

When the split drag rudders are locked in zero degree, yaw movement is significantly reduced and may not be available, so the heading for entering the water should be set before reducing altitude and lock the split drag rudder to enter the water. 

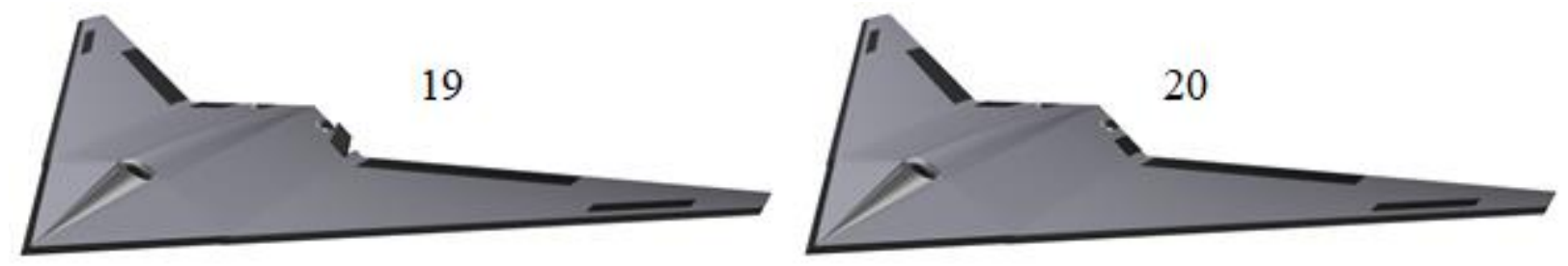

Figure 19: When the left side split drag rudder is in $60^{\circ}$ position

Figure 20: When the left side split drag rudder is in $0^{\circ}$ position

wings have an acute angle to minimize the water surface shock at the time of entry, without acute angle, the water surface shock can damage the leading edge slat, and break off it, make the wings impractical.

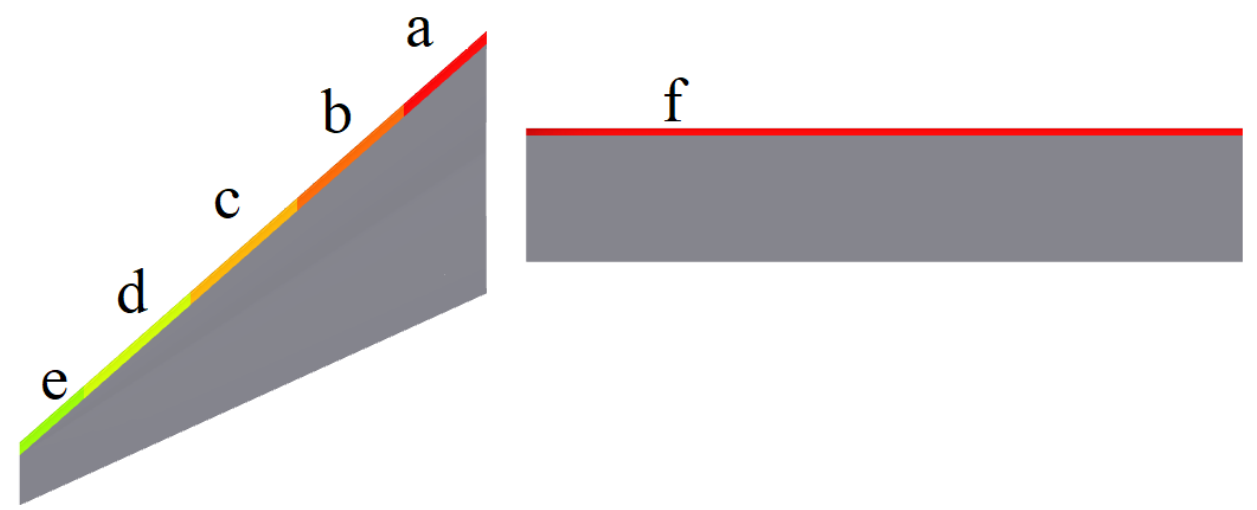

Figure 21: the shock power on leading edge of QFS-20 wing(left) and a rectangular wing(right).

The shock power that wings takes:

$\mathrm{e}<\mathrm{d}<\mathrm{c}<\mathrm{b}<\mathrm{a}=\mathrm{f}$

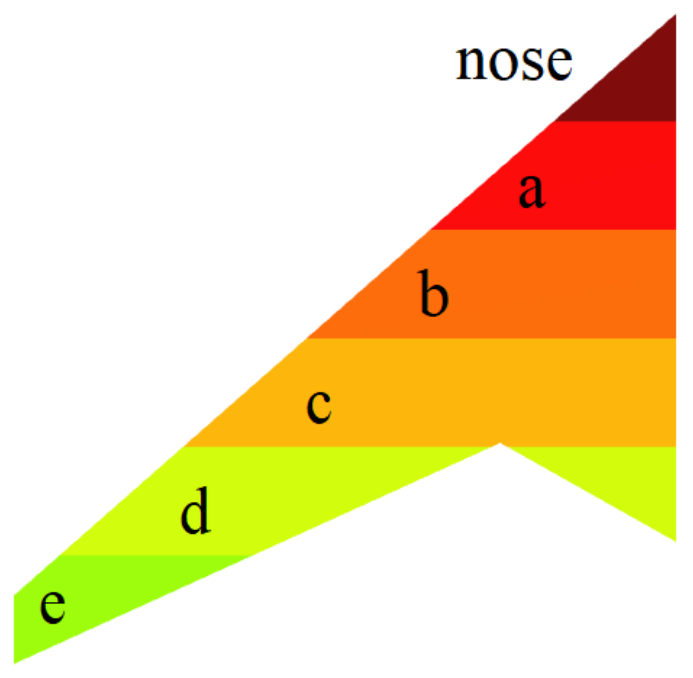

to explain more, QFS-18 has been divided in 7 parts: nose, a, b, c ,d and e; the first part that will touch the water surface is nose, due to the flight speed of QFS-20 while nose impact with water surface, the nose would take the highest shock, because of the impact, QFS-20's speed would reduce, the part "a" would touch the surface of water, taken shock by part "a" would be lower than nose, due to impact of part “a”, QFS-20's speed would reduce. 
This process would repeat several times until QFS-20 has completely entered the water.

\section{IV-flight and underwater travel process}

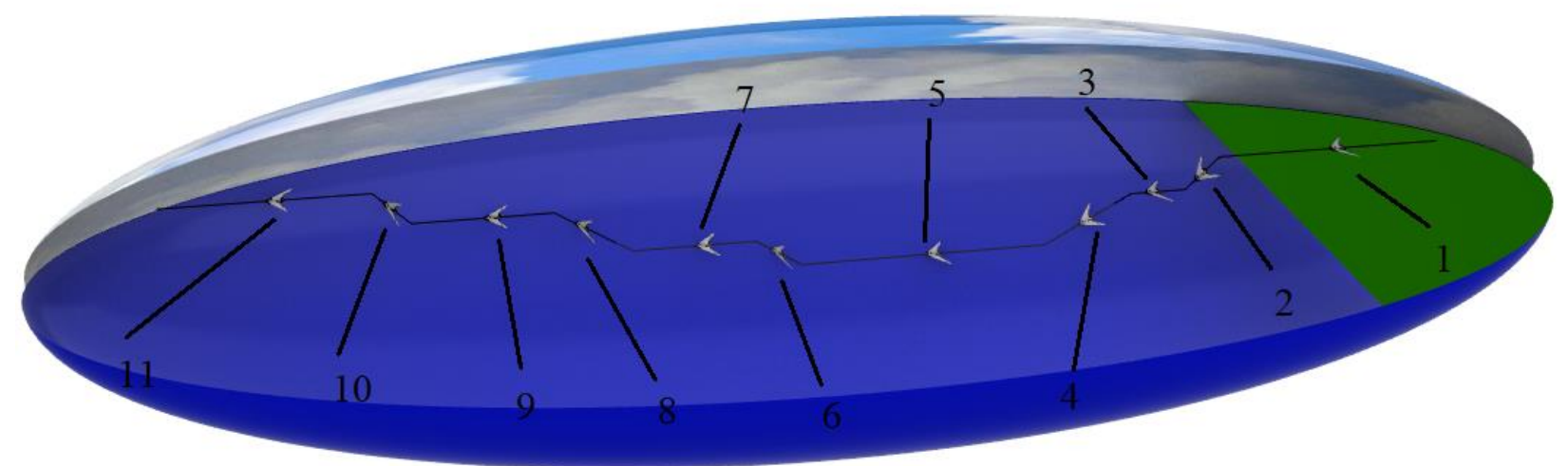

Figure 22: The black line is the way of the process

The flight and underwater travel process includes 4 acts:

- $\quad$ Flying $(1,10,11)$

- Entering the water $(2,3,4)$

- underwater travel (5)

- Exiting the water $(6,7,8,9)$

"Flying" includes the flight time in air and under water travel including entry and exit to and from water. This process should be complete during the QFS-20 missions. All the above are interrelated any inefficiency in any of the processes would have serious implications.

\section{IV.I: Flying}

Flying is the first and the last act of the process, the process starts with taking off, and ends with reducing speed and altitude for entry to water. This is then followed by process of exiting water, gaining altitude, reducing speed and altitude, and landing. The above is the function of the QFS-20 jet engines. 


\section{IV.II: Entering the water}

This is the second act and starts with losing altitude while flying and ends with losing altitude underwater. The jet engines produce the thrust to move QFS-20 while flying and the water engines produce the thrust to move QFS-20 while underwater. When close to water surface QFS-20 will reduce speed to (near the stall speed) and start the water engines before entry to water.

\section{IV.III: underwater travel}

This act is the third act of the process. It includes all of the maneuvers under water and water engines produce the thrust to move QFS-20 in this act. The duration spent under water would depend on a number of factors including; the objective, swimming altitude, fuel, and the pressure that the aero submarine's body is designed for.

\section{IV.IV: exiting the water}

The forth act of the process and starts with gaining altitude to get a short distance to the water surface(underwater), the underwater engines are operating at maximum power supported by speed boosters followed by leveling QFS-20 and turning off the leading edge slat. Upon reaching the required speed for exiting water the leading edge slat will go down and underwater elevator are used. Following exit, the inlet door will go down and stop covering, the jet engine will start working, QFS-20 will use speed boosters to gain speed and altitude after the engine starts producing thrust to complete mission.

\section{$\mathrm{V}$-conclusion}

This paper provided an overview of the aerosub designs and challenges faced in the design of such vehicles. It attempted to provide a theoretical design for an aerosub capable of meeting the requirements of todays applications using the current and available technologies. Whilst additional information in all aspect of the paper would be helpful, the paper highlights the feasibility for further developments and research in this area. 


\section{List of references}

[1]- Y. Chen, E. F. Helbling, N. Gravish, K. Ma and R. J. Wood, "Hybrid aerial and aquatic locomotion in an at-scale robotic insect," 2015 IEEE/RSJ International Conference on Intelligent Robots and Systems (IROS), Hamburg, Germany, 2015, pp. 331-338.

[2]- B.D. Reid, The Flying Submarine: The Story of the Invention of the Reid Flying Submarine, RFS-1, Heritage Books Inc, Berwyn Heights, 2004.

[3]- Polmar, Norman \& Moore, Kenneth J. Cold War submarines: U.S. and Soviet design and construction, Potomac Books, Inc, Virginia,2004.

[4]- G. Petrov, "Flying submarine," Journal of fleet, 1995. [Online]. Available: http://www.airforce.ru/ aircraft/ miscellaneous/ flying submarine/ index.htm [5]- Paulo Drews-Jr, Mario Fernando Montenegro Campos, Armando Alves Neto. Survey on Aerial Submersibe Vehicle. Bremen: IEEE/OES Oceans (2009). [6]- ] A. Fabian, Y.F. Feng, E. Swartz, et al., Hybrid Aerial Underwater Vehicle, MIT Lincoln Lab, Lexington, 2012 (2012 SCOPE Projects).

[7]- Liang, J., Yang, X., Wang, T., Yao, G., \& Zhao, W., Design and Experiment of a Bionic Gannet for Plunge-Diving. Journal of Bionic Engineering, 10(3), 282291 (2013).

[8]- Liang, J., Yao, G., Wang, T. et al. Wing load investigation of the plungediving locomotion of a gannet Morus inspired submersible aircraft. Sci. China Technol. Sci. 57, 390-402 (2014).

[9]- Yang, X., Wang, T., Liang, J., Yao, G., \& Liu, M. Survey on the novel hybrid aquatic-aerial amphibious aircraft: Aquatic unmanned aerial vehicle (AquaUAV). Progress in Aerospace Sciences, 74, 131-151 (2015). .

[10]- R. Siddall, M. Kovač, Launching the AquaMAV: bioinspired design for aerial- aquatic robotic platforms, Bioinspir. Biomim. 9 (3) , 1-15 (2014)

[11]- M. Kovač, The bioinspiration design paradigm: a perspective for soft robotics, Soft Robot. 1, 28-37 (2013) 
[12]- WANG, L., \& WANG, L. Reconfigurable Flight Control Design for Combat Flying Wing with Multiple Control Surfaces. Chinese Journal of Aeronautics, 25(4), 493-499 (2012) 